Alma Mater Studiorum - Università di Bologna DEPARTMENT OF ECONOMICS

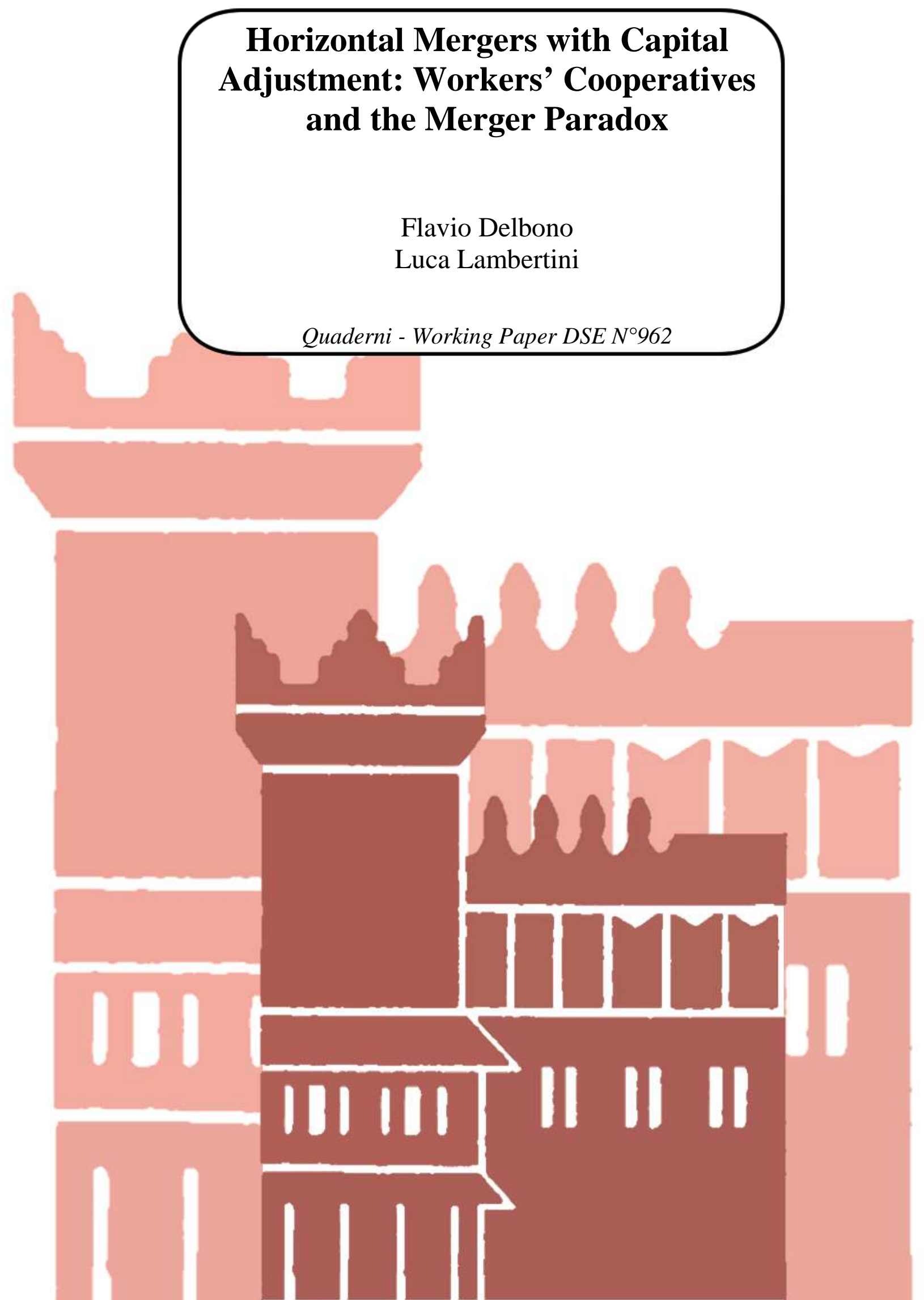




\title{
Horizontal Mergers with Capital Adjustment: Workers' Cooperatives and the Merger Paradox
}

\author{
Flavio Delbono\# ${ }^{\#}$ and Luca Lambertini ${ }^{\S}$ \\ \# Department of Economics, University of Bologna \\ Piazza Scaravilli 2, 40126 Bologna, Italy; flavio.delbono@unibo.it \\ $\S$ Department of Economics, University of Bologna \\ Strada Maggiore 45, 40125 Bologna, Italy; luca.lambertini@unibo.it
}

September 10, 2014

\begin{abstract}
We study the incentives towards horizontal merger among firms when the amount of capital is the strategic variable. We focus on is workers' cooperatives, but our conclusions apply also to employmentconstrained profit maximisers. Within a simple oligopoly model, we prove that the horizontal merger, for any merger size, is: (i) privately efficient for insiders as well as for outsiders; (ii) socially efficient if market size is large enough, even in the case of merger to monopoly.
\end{abstract}

JEL Codes: D43, L13, L21, L41

Keywords: horizontal mergers, workers' co-ops, efficiency effect 


\section{Introduction}

We investigate the consequences of horizontal mergers among firms when the strategic variable is capital. Firms which most seemingly fit such a setting are workers' firms: being owned and managed by workers, their concern about employment stability is likely to be stronger than in other types of firms. Actually, this is what the by now large empirical evidence seems to suggest. ${ }^{1}$

Co-ops play a significant economic role in their communities. A few facts listed in the website of the International Co-op Alliance suffice to convey the dimension of the phenomenon. The co-operative movement brings together over one billion people around the world. Moreover, co-ops are significant players in many national economies. In terms of employment, co-ops provide over a hundred million jobs over the planet (twenty per cent more than multinationals). Both in Italy and in France, they employ in 2005 nearly one million people; in Spain they provide about 250,000 overall jobs in 2012. Almost the same number of employees worked in 2010 in the 5,450 British coops ( $10 \%$ of which were workers' cooperatives). In the US, thirty thousand coops provide more than one million jobs in 2006. The sectorial breakdown of co-ops varies very much across countries, although, unsurprisingly, the co-ops with more members operate in the consumer retail market, where members are the consumers. However, a glance to national figures suggests that the co-operative presence is often significant in the credit market, agriculture and food, housing and construction, health.

In recent years, we are witnessing a resurgence of interest in the cooperative experiences also because co-ops seem to perform better than conventional firms during slums. ${ }^{2}$ If we confine our attention to workers' co-

\footnotetext{
${ }^{1}$ See, for instance, the updated and comprehensive survey by Perotin (2012).

${ }^{2}$ According to Cecop (the largest European association of national co-ops), co-ops are
} 
operatives, ${ }^{3}$ we may observe that the mutuality operating among co-ops helps them limit the number of bankruptcies as compared to conventional firms in turmoil. Such help takes sometimes the strong form of merging: for instance, 30 mergers among Italian production co-ops occurred in 2009 against 47 in the all period 2005-2008.

The rough evidence reported in the next pages suggests that horizontal merging is a fairly frequent strategy undertaken by co-ops managers, especially in periods of poor macroeconomic performance. Notwithstanding the relevance and the frequency of such corporate strategies, to the best of our knowledge there is no formal attempt to model the consequences of horizontal mergers among co-ops. Our paper aims at filling the gap through a simple analysis of an oligopoly formed by workers' co-ops.

Furthermore, we shall see that, since Ward (1958), the standard objective function of a workers' co-op (revenue net of fixed cost divided by the number of members) coincides with profits when labor is kept constant and capital is the only variable input, as originally pointed out by Sertel (1987). Hence, while we focus on horizontal mergers among workers' co-ops, our conclusions also extend to profit-maximising firms constrained by a given level of employment. Our results can then participate in the long-lasting debate affording the ongoing crisis better than non-co-ops, especially as far as employment is concerned. See Delbono and Reggiani (2013) for a descriptive statistics of some Italian industries and the references to other European recent experiences.

${ }^{3}$ Workers' co-operatives are firms owned and managed by their employees. This is a broad definition based on cooperative principles. In a workers' co-op the bulk of the capital is owned (individually or collectively) by employees; all of them are eligible for membership; a majority of the workers are members; each member has one vote. Again, see Perotin (2012). Workers' co-ops are sometimes called 'production' co-ops or 'labor' coops, or labor-managed firms, to stress the contribution of labor directly given by members. 
on the merger paradox, according to which the merger is profitable for the merging firms only if they represent a large majority of the overall firms in the industry. ${ }^{4}$

We show that:

- The horizontal merger is privately efficient for any merger size. This holds for insiders and outsiders as well.

- The horizontal merger is socially efficient if market size is large enough, also in the extreme case of merging to monopoly.

The remainder of the paper is organised as follows. Next section briefly illustrates a sample of episodes of horizontal mergers as corporate strategies of workers' co-operatives in various countries. Section 3 presents the model. Sections 4 characterises the private incentive to carry out the merger. Section 5 performs the analysis of social efficiency of such a merger. The equivalence between the behaviour of a workers' co-operative and a profit-maximising firm when the post-merger adjustment operates on the capital side of the production function is shown in section 6 . Section 7 illustrates the possibility of a socially efficient merger to monopoly. Section 8 concludes.

\section{Mergers among co-ops}

Horizontal mergers among workers' co-ops do not occur only in downturn, as one can be tempted to believe by looking at the recent waves of mergers in the co-op movement. We may cite several examples during the 1980s in the

\footnotetext{
${ }^{4}$ This debate dates back to Salant et al. (1983). In a linear Cournot model, they show that a horizontal merger (without cost benefits) is profitable only if involving at least $80 \%$ of the existing firms.
} 
US agricultural market: FS Services and Illinois grain cooperative forming Growmark Inc. Cooperative; Midland Cooperatives and Land O'Lakes Inc.; Ohio Farmers Grain and Supply and Landmark Inc. The Rural BusinessCooperative Service, an agency of USDA Rural Development, counted 367 merger/consolidation events in the period 1993-1997, most of which occurred in the Corn Belt and Southern Plains regions. ${ }^{5}$

The dairy industry is another sector featuring a high cooperative density in which horizontal mergers occur fairly often. A recent example is the one between Dairylea and DFA, two leading co-ops in the US dairy market. Another one is the merger in 2009 between Friesland Foods and Campina, two major Dutch dairy co-operatives, resulting in a combined market share between 70 and $80 \%$ of the market for the procurement of raw milk in the Netherlands. Again, two Irish leading farmer-owned dairy and agri co-ops (Ballyclough and Mitchelstown) merged in 1990 giving rise to Dairygold Cooperative Society. ${ }^{6}$

Several examples come also from Italy. A merger between two leading co-ops (Consorzio Colli Berici and Cantina di Colognola ai Colli) created in 2007 a new co-op holding more than $2 \%$ of overall Italian wine production. The Italian constructions industry has witnessed two important horizontal mergers between CCC and Consorzio Ravennate delle Coooperative di Pro-

\footnotetext{
${ }^{5}$ For statistical details of this tide of mergers, see the report by Anthony Crooks, "Consolidation in the heartland", which is available online (www.rurdev.usda.gov/rbs/pub/nov00/heart.htm),

${ }^{6}$ To be precise, the examples coming from the dairy market and often from the agricultural market do not fit exactly the definition of workers' co-op, as members give products and not labor to the co-op they belong to. However, tehre is an obvious direct relationship between the labor employed by a member and the amount of product given by her to the co-op.
} 
duzione e Lavoro in 2011, and the one between two bigs of the sector (Unieco and Coopsette) in 2014.

To continue with other examples, we witness also a wave of mergers of agrifood cooperatives in Spain (see Meliá et al., 2010).

\section{The model}

We consider an industry formed by a finite set $\mathcal{N}=1,2,3 \ldots, n$ of workers' co-ops. The demand side is summarised by the function

$$
p=a-Q
$$

where $Q=\sum_{i=1}^{n} q_{i}$ is aggregate output, $q_{i}$ is individual output, $p$ is price and $a$ is a positive parameter. Production takes place according to the following technology:

$$
q_{i}=l \sqrt{k_{i}}
$$

where $l \geq 2$ is the constant number of workers/members in each firm, and $k_{i}>0$ denotes the amount of capital installed in firm $i$. We focus on 'pure' co-ops in which all workers are also members and conversely. ${ }^{7}$ According to a well established tradition in the literature, we model firm $i$ 's objective function as value added per worker/member:

$$
V_{i}=\frac{p q_{i}-k_{i}}{l}=\frac{\left(a-l \sqrt{k_{i}}-l \sum_{j \neq i} \sqrt{k_{j}}\right) l \sqrt{k_{i}}-k_{i}}{l}
$$

\footnotetext{
${ }^{7}$ This is not an unreasonable assumption. For instance, the average membership ratio (number of members out of the number of workers) in Italian workers' co-ops is about 0.75 (cf. Zanotti, 2012). Italy is the country with the highest number of workers' co-ops in the world (more than 30,000 in 2008, according to Zanotti, 2012).
} 
We shall follow Sertel (1987) in keeping membership constant ${ }^{8}$ (and, for simplicity, identical across firms) so that the only variable input is capital; $k_{i}$ is then the strategic variable in the non-cooperative game we are about to describe.

Although we are modelling a game in the space of capital amounts, this is equivalent to a standard Cournot-Nash game in output levels. To see this, note that (2) is invertible, and therefore it can be rewritten as

$$
k_{i}=\frac{q_{i}^{2}}{l^{2}}
$$

in such a way that the objective function (3) rewrites as:

$$
V_{i}=\frac{p q_{i}-k_{i}}{l}=\frac{q_{i}\left[l^{2}\left(a-q_{i}-\sum_{j \neq i} q_{j}\right)-q_{i}\right]}{l^{3}}
$$

Coming back to our formulation (3), the status quo ante is then the Nash equilibrium in the space of capital levels. The first order condition (FOC) of firm $i$ is:

$$
\frac{\partial V_{i}}{\partial k_{i}}=\frac{l\left(a-l \sum_{j \neq i} \sqrt{k_{j}}\right)-2\left(1+l^{2}\right) \sqrt{k_{i}}}{2 l \sqrt{k_{i}}}=0
$$

Imposing the symmetry condition $k_{j}=k_{i}=k$ on (6) and solving w.r.t. $k$, we get the expression of the Nash equilibrium level of capital:

$$
k^{N}(n)=\frac{a^{2} l^{2}}{\left[2+l^{2}(n+1)\right]^{2}}
$$

where superscript $N$ mnemonics for Nash equilibrium. ${ }^{9}$ The resulting value

\footnotetext{
${ }^{8} l$ may be decomposed as follows. If $L$ is the number of workers (coinciding with the number of members) in a firm and $\ell$ is the number of hours worked per person in the same firm, then $l=L \ell$. Since we take $l$ as exogenously given, this is immaterial.

${ }^{9}$ In correspondence of $k^{N}(n)$, the second order condition is always met as

$$
\frac{\partial^{2} V_{i}}{\partial k_{i}^{2}}=-\frac{\left(1+l^{2}\right)\left[2+l^{2}(n+1)\right]^{2}}{2 a^{2} l^{3}}<0
$$

everywhere.
} 
added at equilibrium is:

$$
V^{N}(n)=\frac{a^{2}\left(1+l^{3}\right)}{\left[2+l^{2}(n+1)\right]^{2}}
$$

and the associated equilibrium price is

$$
p^{N}(n)=\frac{a\left(2+l^{2}\right)}{2+l^{2}(n+1)} .
$$

\section{The horizontal merger: private incentives}

We now consider a horizontal merger among $m \in[2, n-1]$ co-ops. Given the nature of a workers' co-op, it seems reasonable to assume that the membership of the firm resulting from the merger is the sum of ex ante memberships of the merging firms, with the adjustment taking place along the capital dimension only. ${ }^{10}$ That is to say, the total number of workers/members in the new firm resulting from the merger will be $\mathrm{ml}$. As a result of the merger, we will observe $n-m+1$ independent firms acting on the market. Hence, one has to compute the FOCs for the company resulting from the merger (labelled $M$ ) and the $n-m$ outsiders, to be taken on the following objective functions, respectively:

$$
\begin{gathered}
V_{M}=\frac{\left(a-m l \sqrt{k_{M}}-l \sum_{j=1}^{n-m} \sqrt{k_{j}}\right) m l \sqrt{k_{M}}-k_{M}}{m l} \\
V_{i}=\frac{\left(a-m l \sqrt{k_{M}}-l \sqrt{k_{i}}-l \sum_{j=1}^{n-m-1} \sqrt{k_{j}}\right) l \sqrt{k_{i}}-k_{i}}{l}
\end{gathered}
$$

Therefore, the relevant FOCs are:

$$
\frac{\partial V_{M}}{\partial k_{M}}=\frac{m l\left(a+l \sum_{j=1}^{n-m} \sqrt{k_{j}}\right)-2\left(1+l^{2} m^{2}\right) \sqrt{k_{M}}}{2 l \sqrt{k_{M}}}=0
$$

\footnotetext{
${ }^{10}$ Many empirical papers surveyed by Perotin (2012) confirm that workers' co-ops tend to stabilise employment in the short-run reaction to shocks.
} 


$$
\frac{\partial V_{i}}{\partial k_{i}}=\frac{l\left[a-l\left(m \sqrt{k_{M}}+\sum_{j=1}^{n-m-1} \sqrt{k_{j}}\right)\right]-2\left(1+l^{2}\right) \sqrt{k_{i}}}{2 l \sqrt{k_{i}}}=0
$$

Now, imposing the symmetry condition $k_{i}=k_{j}=k_{\text {out }}$ across the population of outsiders (denoted by the subscript out), we can solve the above system of FOCs w.r.t. $k_{M}$ and $k_{\text {out }}$ :

$$
\begin{aligned}
k_{M}^{N} & =\frac{a^{2} l^{2} m^{2}\left(2+l^{2}\right)^{2}}{\left[4+l^{4} m^{2}(2+n-m)+2 l^{2}(n+1+m(2 m-1))\right]^{2}} \\
k_{\text {out }}^{N} & =\frac{a^{2} l^{2}\left(2+l^{2} m^{2}\right)^{2}}{\left[4+l^{4} m^{2}(2+n-m)+2 l^{2}(n+1+m(2 m-1))\right]^{2}}
\end{aligned}
$$

From a straightforward comparison between $k_{\text {out }}^{N}, k_{M}^{N}$ and $k^{N}(n)$, we can claim:

Remark 1 For any merger of size $m \in[2, n-1]: k_{M}^{N}<m k^{N}(n)$, while $k_{\text {out }}^{N}>k^{N}(n)$; and $k_{M}^{N}<k_{\text {out }}^{N}$.

Hence, the post-merger capital adjustment operates in opposite directions for insiders and outsiders. While the former contract their capital w.r.t. the pre-merger Nash equilibrium, the latter expand it. As a result, the new company invests less than each of the $n-m$ outsiders.

Given the ex post distribution of memberships, we look now at the consequences in terms of equilibrium price and industry output:

Proposition 2 Any merger of size $m \in[2, n-1]$ brings about an increase in price (and a reduction in industry output).

Proof. The ex post equilibrium price is

$$
p_{M}^{N}=\frac{a\left(2+l^{2}\right)\left(2+l^{2} m^{2}\right)}{4+l^{4} m^{2}(2+n-m)+2 l^{2}(n+1+m(2 m-1))}
$$


Comparing (16) and (9), we have

$p_{M}^{N}-p^{N}(n)=\frac{a l^{2}\left(2+l^{2}\right)(m-1) m\left(l^{2} m-2\right)}{\left[2+l^{2}(n+1)\right]\left[4+l^{4} m^{2}(2+n-m)+2 l^{2}(n+1+m(2 m-1))\right]}$

which is positive everywhere. Therefore, $Q_{M}^{N}<Q^{N}(n)$.

We may disentangle the driving forces behind the increase in price by looking at the consequences of merger on individual output levels:

Remark 3 The merging firms contract their output w.r.t. the pre-merger levels (i.e., $\left.q_{M}^{N}<m q^{N}(n)\right)$ while the opposite occurs to all outsiders (i.e., $\left.q_{\text {out }}^{N}>q^{N}(n)\right)$.

The final effect on price shows that the contraction in the output of the merging firms outweighs the expansion on the part of the outsiders.

These effects of the merger on output levels and price, in turn, are the consequence of the variations in the amounts of capital caused by the merger, as summarised in Remark 1 above.

We are now ready to tackle the key question of the private incentives to merge. The ex post level of value added per worker/member is:

$$
V_{M}^{N}=\frac{a^{2} l m^{2}\left(2+l^{2}\right)^{2}\left(1+l^{2} m^{2}\right)}{\left[4+l^{4} m^{2}(2+n-m)+2 l^{2}(n+1+m(2 m-1))\right]^{2}}
$$

for the firm generated by the merger, and

$$
V_{\text {out }}^{N}=\frac{a^{2} l\left(1+l^{2}\right)\left(2+l^{2} m^{2}\right)^{2}}{\left[4+l^{4} m^{2}(2+n-m)+2 l^{2}(n+1+m(2 m-1))\right]^{2}}
$$

for any of the $n-m$ outsiders.

To establish the existence of a private incentive to carry out the merger, we need to compare $V_{M}^{N}$ with $V^{N}(n)$. Iff $V_{M}^{N}>V^{N}(n)$, any of the $m l$ workers/members would vote in favour of the merger. We are about to show that this is always the case. 
Proposition $4 V_{M}^{N}>V^{N}(n)$ for all $m \in[2, n-1]$.

Proof. The sign of $V_{M}^{N}-V^{N}(n)$ is the sign of:

$$
\begin{gathered}
16(m+1)+l^{10} m^{4}(3+2 n-m)+ \\
4 l^{4}[5+m(2 m(2 m+5)-1)]+6 n+4 n m[m(m+1)+1]+n^{2}(m+1)+ \\
16 l^{2}[2+n+m(m(m+1)+n+1)]+ \\
4 l^{6}\left[2 m^{4}+(n+1)^{2}+m^{2}(n+2)(n+4)+m\left(n^{2}-1\right)+m^{3}(n(n+4)-1)\right]+ \\
l^{8} m^{2}\left[7-m(5+m(m-11))+10 n+2 n m(m+1)+3 n^{2}(m+1)\right]
\end{gathered}
$$

The expressions appearing in the five lines of (20) are all positive because $n>m$. Hence, $V_{M}^{N}>V^{N}(n)$.

Concerning outsiders, the consequences of the merger are summarised by the following:

Proposition 5 For all $m \in[2, n-1]$, the horizontal merger increases the outsiders' payoffs.

Proof. It suffices to note that

$$
\begin{gathered}
\operatorname{sign}\left\{V_{\text {out }}^{N}-V^{N}(n)\right\}= \\
\operatorname{sign}\left\{8+l^{2}\left[4(n+1)+m\left(m\left(6+l^{2}(2 n+3-m)\right)-2\right)\right]\right\}
\end{gathered}
$$

with the expression on the r.h.s. being positive for all $m \in[2, n-1]$.

Therefore, the merger always exerts a positive spillover on outsiders. 


\section{Welfare analysis}

We now assess the welfare consequences of the horizontal merger. As is common practice in partial equilibrium analysis, social welfare is defined by the sum of consumer and producer surplus. In our setting, however, it would be inappropriate to identify producer surplus with profits, as the ultimate goal of firms is value added per worker. Hence, we use total revenue net of the industry amount of capital as a measure of producer surplus:

$$
P S=p Q-n k
$$

To understand why this is the appropriate measure of the surplus accruing to firms, notice that we should multiply the level of the value added per worker/member by the total number of workers/members in the industry:

$$
P S=n l\left(\frac{p q-k}{l}\right)
$$

which yields precisely (22). As for the consumer surplus, defined as usual by the area below the demand function and above the market price, it is given by $C S=Q^{2} / 2$.

Then, in the pre-merger equilibrium, social welfare is

$$
S W^{N}(n)=P S^{N}(n)+C S^{N}(n)=\frac{a^{2} l^{2} n\left[2+l^{2}(n+2)\right]}{2\left[2+l^{2}(n+1)\right]^{2}}
$$

The full expression of the post-merger social welfare is given by the sum of gross total revenue and consumer surplus minus total capital expenditure:

$$
S W_{M}^{N}=p_{M}^{N}\left(a-p_{M}^{N}\right)+C S_{M}^{N}-k_{M}^{N}-(n-m) k_{\text {out }}^{N}
$$

where

$$
C S_{M}^{N}=\frac{\left(a-p_{M}^{N}\right)^{2}}{2}=
$$




$$
\frac{a^{4} l^{4}\left[4 n+m\left(m\left(4\left(1+l^{2}(n-m+1)\right)+l^{4}\left(1+m^{2}(n-m)\right)\right)-4\right)\right]^{2}}{2\left[4+l^{4} m^{2}(n-m+2)+2 l^{2}(n+1+m(2 m-1))\right]^{4}}
$$

The social (in)efficiency of the horizontal merger has to be evaluated through of the sign of

$$
\Delta S W \equiv S W_{M}^{N}-S W^{N}(n)
$$

The examination of (27) leads to the following result:

Proposition $6 \Delta S W>0$ for all $a>\max \left\{0, a_{+}\right\}$.

Proof. $\triangle S W$ may be written as a quadratic function of $a$ :

$$
\Delta S W(a)=\alpha(l, m, n) a^{2}+\beta(l, m, n) a+\gamma(l, m, n)
$$

where $\alpha(\cdot), \beta(\cdot)$ and $\gamma(\cdot)$ are polynomials. Our result rests on the analysis of $\alpha(\cdot)$ :

$$
\begin{gathered}
\alpha(l, m, n)=l^{2}\left[2+l^{2}(n+1)\right]^{2}[4 n+m \Psi]^{2} \\
\Psi \equiv\left(m\left(4\left(1+l^{2}(n-m+1)\right)+l^{4}\left(1+m^{2}(n-m)\right)\right)-4\right)
\end{gathered}
$$

which is always positive. Consequently, we envisage four possible (and mutually exclusive) scenarios:

i) The two solutions of $\Delta S W(a)=0$ w.r.t. $a$ are both negative. In this case, the merger is socially efficient for all $a>0$.

ii) $\Delta S W(a)=0$ has no real solutions. In this case, the same conclusion as in case (i) applies.

iii) $\Delta S W(a)=0$ has two real solutions of opposite sign, $a_{-}<0<a_{+}$. In this case, $\Delta S W(a)>0$ for all $a>a_{+}$.

iv) $\Delta S W(a)=0$ has two real solutions, both positive: $0<a_{-}<a_{+}$. Here, the merger is surely socially efficient for all $a>a_{+} \cdot{ }^{11}$

\footnotetext{
${ }^{11}$ The overlong expressions of $\alpha(\cdot), \beta(\cdot)$ and $\gamma(\cdot)$, as well as $a_{ \pm}$are available upon request from the authors.
} 


\section{The profit-seeking industry}

So far, we have focussed on workers' co-operatives because the assumption of the stability in employment best fits this type of firms. However, the same behavior can originate also from a profit-seeking firm subject to constraints on the number of employees. This might be the case with publicly-owned enterprises (e.g., several utilities in Europe) as well as with privately-owned firms operating in strongly unionised industries.

It can be easily shown that, when the amount of labour is fixed, the maximisation of value added per worker amounts to maximising profits. To see this, observe that since

$$
V_{i}=\frac{p q_{i}-k_{i}}{l}
$$

and profits are

$$
\pi_{i}=p q_{i}-w l-k_{i},
$$

where $w$ is the unit wage; then

$$
V_{i}=\frac{\pi_{i}}{l}+w
$$

which in turn also implies that $V_{i}>w$, otherwise the members of the cooperative would quit it to offer their labor elsewhere. Clearly, given $l$ and $w$, the value of $k_{i}$ maximising $\pi_{i}$ coincides with the level which maximises value added per worker/member. Consequently, the private and social incentives towards the merger are identical under the two firms' maximands.

For our model applies to horizontal mergers among profit-seekers too, the foregoing analysis may shed some light also on the debate about the merger paradox mentioned in the introduction. In such a debate, the focus was on the consequences of a merger under different assumptions about the nature of returns in production, the latter being summarised by the properties of 
costs as a function of output. ${ }^{12}$ A classical example emerging from such a debate involves the lack of a profit incentive to carry out a merger between two firms out of three enterprises in the industry. An elementary exercise consisting in setting $n=3$ and $m=2$ in (20) suffices to detect that in our setup such a merger is efficient for the merging firms irrespective of whether they aim at maximising profit or individual value added, as the incentive to merge reduces to

$$
V_{M}^{N}(2)-V^{N}(3)=\frac{a^{2} l\left[3+l^{2}\left(25+72 l^{2}+91 l^{4}+45 l^{6}+7 l^{8}\right)\right]}{4\left[1+l^{2}\left(7+13 l^{2}+6 l^{4}\right)\right]^{2}}
$$

which is strictly positive, and therefore also $\pi_{M}^{N}(2)>\pi^{N}(3)$. The sign of (33) is clearly a straightforwad consequence of our Proposition 4. the lesson we may draw from (33) is that, if one models technology through a wellbehaved production function instead of a cost function, under the constraint of a constant employment level, the standard textbook example of the merger paradox does not hold anymore. ${ }^{13}$

\section{$7 \quad$ Efficiency effect and merger to monopoly}

Through the initial assumption $m \in[2, n-1]$, we have ruled out, so far, the merger to monopoly. Yet, as the per-firm (and therefore industry) employment is bound to be constant, the following can be easily established:

Proposition 7 There exists a market size $\widetilde{a}$ above which the merger to monopoly is socially efficient.

\footnotetext{
${ }^{12}$ The debate, inaugurated by Salant et al. (1983), include Perry and Porter (1985) and Farrell and Shapiro (1990), among others.

${ }^{13}$ Such example, borrowed from Salant et al. (1983), shows, indeed, that in a triopoly, the only profitable merger is the one to monopoly.
} 
We omit the explicit expression of $\widetilde{a}$, which can be easily computed by posing $m=n$ and solving $\Delta S W=0$ w.r.t. $a$, and indeed corresponds to $a_{+}$ in $m=n$. The rationale behind this result can be explained relying upon the efficiency effect generated by the reduction of capital equipment. For the merger succeeds in shrinking the overall amount of capital by reducing the duplication of plants, this effect can more than compensate the extreme reduction in consumer surplus generated by monopoly pricing.

This conclusion has a definite Schumpeterian flavour. In fact, the postmerger contraction in the level of capital corresponds to a leftward movement along the production function (where capital is the only variable input). Given the properties of our production function, the new point along it is associated to a higher marginal productivity of capital w.r.t. the premerger situation. Hence, we may think of this adjustment as equivalent to the outcome of capital-saving $\mathrm{R} \& \mathrm{D}$ activity undertaken by the monopolist resulting from the merger. The efficiency effect that we have just envisaged strengthens the argument put forward by Farrell and Shapiro (1990) when discussing the efficiency defence associated with restructuring of plants (and therefore abating fixed costs). Moreover, our horizontal merger squarely fits the category of beneficial concentrations in the sense of Daughety (1990).

\section{Concluding remarks}

In this paper, we have shown that the horizontal merger, for any merger size, is: (i) privately efficient for insiders as well as for outsiders; (ii) socially efficient if market size is large enough. Moreover, also merging to monopoly can be socially desirable. We have focussed on workers' cooperatives, but our results apply also to employment-constrained profit-seeking firms. 
It is worth noting that our model encompasses the frequently observed case of mixed oligopoly, e.g. industries in which profit-seeking firms coexist with workers' co-ops. As long as they are both constrained on the employment side, although for different reasons, our results fully extend to such a mixed industry, and therefore the incentives to merge that we have outlined above would hold for a merger among profit-seekers and workers' co-ops.

A promising line of research would likely consist in explicitly modelling the dynamics of capital adjustment in a differential game, possibly accounting for the dynamics of the business cycle as well. Such a model might succeed in explaining the empirical observation of waves of horizontal mergers among workers' co-ops during slums. 


\section{References}

[1] Daughety, A. (1990), "Beneficial Concentration", American Economic Review, 80, 1231-37.

[2] Delbono, F. and C. Reggiani (2013), "Cooperative firms and the crisis: evidence from some Italian mixed oligopolies", Annals of Public and Cooperative Economics, 84, 383-97.

[3] Farrell, J. and C. Shapiro (1990), "Horizontal Mergers: An Equilibrium Analysis", American Economic Review, 80, 107-26.

[4] Meliá, E., J.F. Juliá and A. Martinez (2010), "Mergers of Agrifood Cooperatives and Their Effects: From Expectations to Results. An Empirical Study in Four Spanish Autonomous Regions", Spanish Journal of Agricultural Research, 8, 235-50.

[5] Perotin, V. (2012), "The Performance of Workers Cooperatives", in Battilani, P., Schroter, H. (eds), The Cooperative Business Movement, 1950 to the Present, Cambridge, Cambridge University Press.

[6] Perry, M. and R. Porter (1985), "Oligopoly and the Incentive for Horizontal Merger", American Economic Review, 75, 219-27.

[7] Salant, S., S. Switzer and R. Reynolds (1983), "Losses from Horizontal Merger: The Effects of an Exogenous Change in Industry Structure on Cournot-Nash Equilibrium", Quarterly Journal of Economics, 98, 185213.

[8] Sertel, M. (1987), "Workers' Enterprises Are Not Perverse", European Economic Review, 31, 1619-25. 
[9] Ward, B. (1958), "The Firm in Illyria: Market Syndicalism", American Economic Review, 48, 566-89.

[10] Zanotti, A. (2012), "The Strength of an Intersectorial Network", in Zevi, A. et al. (eds), Beyond the Crisis: Cooperatives, Work, Finance, Cecop, Brussels. 


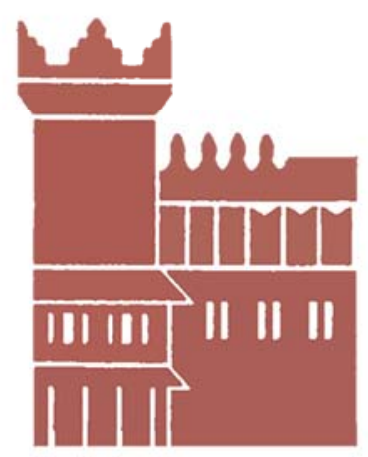

Alma Mater Studiorum - Università di Bologna DEPARTMENT OF ECONOMICS

Strada Maggiore 45

40125 Bologna - Italy

Tel. +39051 2092604

Fax +390512092664

http://www.dse.unibo.it 